\title{
Methicillin-Resistant Staphylococcus Aureus Pneumonia
}

National Cancer Institute

\section{Source}

National Cancer Institute. Methicillin-Resistant Staphylococcus Aureus Pneumonia. NCI

Thesaurus. Code C122523.

Pneumonia that is caused by Staphylococcus aureus and is resistant to methicillin treatment. 